\title{
ОПЕРАТИВНОСТЬ РАЗВИТИЯ СИСТЕМЫ САМОРЕГУЛЯЦИИ ПРОФЕССИОНАЛЬНОЙ ДЕЯТЕЛЬНОСТИ
}

\author{
Ю.П. ПОВАРЕНКОВ
}

a ФГБОУ ВО «Ярославский государственный педагогический университет им. К.Д. Уиинского», 150000, Россия, Ярославль, ул. Республиканская, д. 108/1

\section{Резюме}

Статья посвящена актуальной проблеме изучения оперативности профессионального развития личности. Показано, что основоположником теории оперативности является Д.А. Ошанин, который исследовал образные формы проявления оперативности. Следующий этап развития теории оперативности связан с именем В.Д. Шадрикова. Средствами теоретического и эмпирического анализа он показал, что в соответствии с принципами оперативности развивается не только оперативный образ, но и подсистема профессионально важных качеств личности. В настоящей статье предпринята попытка эмпирически доказать, что принципам оперативности подчиняются также формирование и реализация системы саморегуляции профессиональной деятельности. С этой целью авторами проведен теоретический анализ понятия оперативности и дано его определение. Обозначен подход к пониманию саморегуляции деятельности, который реализован в исследовании. Осуществлен сопоставительный эмпирический анализ систем саморегуляции деятельности врачей общей практики и хирургов, а также учителей начальной и старшей школы. На количественном, качественном и структурном уровнях определена специфика развития систем саморегуляции различных видов профессиональной деятельности. Выявлены статистически достоверные взаимосвязи между уровнем сформированности компонентов системы саморегуляции и эффективностью деятельности. Было показано, что чем сильнее профессиональные деятельности отличаются друг от друга, тем в большей степени различаются их системы саморегуляции, прежде всего на качественном и структурном уровнях. Полученные результаты были использованы для доказательства оперативности развития системы саморегуляции деятельности.

Ключевые слова: оперативность профессионального развития, сознательная саморегуляция профессиональной деятельности, система саморегуляции, общие способности.

\section{Введение}

Основоположником психологической теории оперативности, как известно, является Д.А. Ошанин. Подчеркивая фундаментальную роль оперативности в 
жизнедеятельности человека, Д.А. Ошанин отмечает: «Оперативность, т.е. тонкая и гибкая приспособимость к условиям деятельности в зависимости от ее задач, стала одной из фундаментальных особенностей человека как динамической системы... В самом общем смысле слова мы называем оперативностью способность человека преодолевать неопределенность ситуаций (избыточность форм отношения к ним), его способность изменять в очень широких диапазонах параметры своего поведения, настраиваясь на успешное выполнение встающих перед ним задач» (Ошанин, 1999, с. 187).

Д.А. Ошанин утверждал, что оперативность проявляется не только на уровне отражения объективной и субъективной реальности, основное его внимание было сосредоточено на изучении формирования и функционирования оперативного образа (Ошанин, 1977). Поэтому, возможно, за рамками его теоретического и эмпирического анализа остались другие формы проявления оперативности.

На этот факт обратил внимание В.Д. Шадриков, с именем которого связан следующий этап развития психологической теории оперативности. В своих исследованиях он показал, что закономерности оперативности, выявленные Д.А. Ошаниным (Ошанин, 1970), проявляются и в процессе развития профессиональных способностей человека как субъекта деятельности (Шадриков, 2010). Опираясь на концепцию функциональных, операционных и мотивационных механизмов развития психических функций Б.Г. Ананьева (Ананьев, 1977, с. 206-207), В.Д. Шадриков выявил механизмы развития оперативности профессиональных способностей или, говоря более широко, профессионально важных качеств человека (Шадриков, 2010). Характеризуя данный процесс, В.Д. Шадриков отмечает: «Способности человека как субъекта деятельности развиваются на базе природных способностей индивида. Под влиянием требований деятельности природные способности индивида приобретают черты оперативности, развиваются операционные механизмы, природные способности включаются в психологические функциональные системы, реализующие предметную и идеальную деятельность» (Там же, с. 123).

Итак, основы психологической теории оперативности были заложены Д.А. Ошаниным при изучении образных компонентов профессионального познания человека. Он выделил ведущие свойства (или признаки) оперативного образа, которые, с соответствующими поправками, можно рассматривать в качестве признаков развития оперативности различных психологических систем. К этой группе относятся следующие свойства: прагматичность, адекватность решаемым задачам, специфичность, лаконичность, функциональная деформация.

В дальнейшем разработка данной теории осуществлялась В.Д. Шадриковым, который опирался на результаты исследования развития психологической системы деятельности и подсистемы профессиональных способностей. Вместе с тем есть все основания утверждать, что основные положения теории оперативности нуждаются в дальнейшем уточнении и конкретизации, поскольку не исследованы специфические виды проявления оперативности в процессе развития других психологических компонентов личности и деятельности профессионала. 
К числу таких компонентов можно отнести структуру профессионального самосознания, структуру личности профессионала и ее подструктур, способ деятельности профессионала, систему ее саморегуляции и ряд других. Учитывая важную роль, которую играет в деятельности профессионала система ее саморегуляции, мы сформулировали следующую гипотезу, проверку которой осуществляем в рамках настоящей работы: система саморегуляции профессиональной деятельности развивается в соответствии с принципами оперативности, т.е. ее состав, структура и уровень развития компонентов отражают специфику регулируемой профессиональной деятельности и адекватны задачам, на решение которых она ориентирована. Мы предполагаем, что чем больше различаются между собой анализируемые виды профессиональной деятельности по форме, содержанию, предмету, задачам и т.д., тем в большей степени должны различаться между собой соответствующие им системы саморегуляции деятельности по выделенным признакам. А это и является эмпирическим показателем оперативности их развития.

Но прежде чем приступить к проверке данной гипотезы, остановимся на кратком анализе подходов к пониманию саморегуляции. В целом надо признать, что саморегуляция и различные формы ее проявления активно изучаются отечественными (см.: Моросанова, 2007) и зарубежными психологами (Baumeister, Vohs, 2004; Butler, Winne, 1995; Carver, Scheier, 2003; Schunk, Zimmerman, 2003). Одними из первых в отечественной психологии проблему саморегуляции деятельности стали разрабатывать О.А. Конопкин и его ученики. Напомним, что в 1973 г. под редакцией О.А. Конопкина и Д.А. Ошанина вышел первый в отечественной психологии сборник, посвященный анализу различных аспектов саморегуляции деятельности и ее связям с проблематикой оперативности образа.

Осознанная саморегуляция понимается О.А. Конопкиным как системно организованный процесс внутренней психической активности человека по инициации, построению, осуществлению, поддержанию всех видов активности, которые направлены на достижение принимаемых субъектом целей, и управлению ими (Конопкин, 2005).

О.А. Конопкин отмечает, что саморегуляция существует как общая способность человека, являющегося субъектом своей активности, и как процесс реализации этой способности в конкретных единичных актах деятельности, поведения, общения (Конопкин, 2007). Именно понимание саморегуляции как общей способности позволяет предположить, что, развиваясь в ходе профессионализации, она может приобретать черты оперативности, необходимые для эффективной саморегуляции конкретной профессиональной деятельности (Шадриков, 2013).

Подчеркивая неразрывную связь деятельности и ее саморегуляции, О.А. Конопкин делает следующий методологически важный вывод: «Феномен субъективной регуляции нельзя ограничивать узким контекстом исполнительской деятельности, так как это является неправомерным упрощением и обеднением процесса саморегуляции, которая теряет сущностный для 
нее субъективный аспект, связанный с самостоятельным построением и детерминацией деятельности...» (Конопкин, 2007, с. 15).

Из сказанного следует, что у деятельности и саморегуляции как специфической формы активности разные предметы: предметом саморегуляции как раз и является создание психологической структуры деятельности и ее компонентов. Саморегуляция по отношению к деятельности выступает, по терминологии А.В. Карпова, как метадеятельность (Карпов, 2007). Специфика саморегуляции как метапрофессиональной формы деятельности человека раскрыта в наших работах (Поваренков, 2016, 2017, 2018).

В.Д. Шадриков рассматривает саморегуляцию как механизм становления субъекта деятельности на основе организации, структурирования и переструктурирования ее психологической системы. С позиций системогенетического подхода В.Д. Шадрикова, саморегуляция - это организация личностью своей активности в направлении мобилизации собственных ресурсов в соответствии с мотивацией и целью деятельности (Шадриков, 2010, с. 146).

Важный вклад в разработку психологической теории саморегуляции деятельности и поведения внесла В.И. Моросанова (Моросанова, Коноз, 2000; Моросанова, 2010; Моросанова, Бондаренко, 2015). Она определяет произвольную осознанную саморегуляцию как «системный многоуровневый процесс психической активности человека по выдвижению целей и управлению их достижением» (Моросанова, 2010, с. 37).

Следует отметить, что, несмотря на большое количество проводимых исследований саморегуляции деятельности, практически отсутствуют работы, посвященные сравнительному анализу саморегуляции различных видов профессиональной деятельности. Основное внимание уделяется (Моросанова, Бондаренко, 2015) исследованию саморегуляции учебной деятельности школьников и студентов, саморегуляции спортивной подготовки.

Цель настоящего исследования заключается в том, чтобы выявить количественные, качественные и структурные особенности развития системы саморегуляции деятельности у представителей разных профессий (в данном случае педагогов и врачей) и разных специальностей (врачи общей практики и хирурги; педагоги начальной и старшей школы). Результаты проведенной диагностики мы будем рассматривать в качестве эмпирической основы для анализа специфических особенностей проявления оперативности в процессе развития систем саморегуляции различных видов профессиональной деятельности с учетом выделенных Д.А. Ошаниным базовых признаков оперативности (прагматичность, адекватность решаемым задачам, специфичность, лаконичность, функциональная деформация).

Мы исходим из того, что выявленные на материале изучения оперативного образа свойства и признаки оперативности некорректно механически использовать для анализа оперативности развития системы саморегуляции профессиональной деятельности, поэтому в качестве ведущего критерия развития оперативности системы саморегуляции деятельности будем рассматривать ее специфичность, которая непосредственно связана и с прагматичностью, и с адекватностью, и с другими свойствами. 


\section{Методы и процедура исследования}

В качестве испытуемых в эмпирической части исследования были привлечены педагоги и врачи как представители одной группы профессий «человек-человек» по классификации Е.А. Климова. Обследовались педагоги начальной (1-4-х классов) и старшей (5-11-х классов) школы, а также врачи двух специальностей - общей практики и хирурги. При выделении двух типов педагогов и двух типов врачей мы опирались на результаты психологического анализа их деятельности (Шадриков, 2007) и литературные источники, в которых фиксировалась их профессиональная специфичность.

В исследовании приняли участие 290 педагогов начального и старшего звена обучения. Средний возраст педагогов - 38 лет, а средний педагогический стаж - 16.6 года. Врачей было обследовано 122 человека, их средний возраст - 42.2 года, а средний профессиональный стаж - 16.8 года. В сборе эмпирических данных принимали участие наши аспиранты О.Б. Нурлигаянова, А.Н. Сидорова, О.Ю. Богачева.

Для диагностики развития системы сознательной саморегуляции деятельности использовалась методика В.И. Моросановой «Стиль саморегуляции поведения-ССП» («ССП-98») (Моросанова, Коноз, 2000). Методика качественно валидизирована, прошла психометрическую проверку и широкую апробацию, которая подтвердила ее диагностическую эффективность.

Методика позволяет диагностировать уровень развития 1) процессуальных компонентов системы саморегуляции (условные обозначения: планирование Пл, моделирование - М, программирование - Пр, оценивание результатов Op); 2) регуляторно-личностные качества (условные обозначения: гибкость Г, самостоятельность - C), которые можно назвать регулятивно важными качествами личности. Мы будем использовать обобщающие термины: процессуальный компонент (Проц) и личностный компонент (Лич) саморегуляции.

Оценка эффективности профессиональной деятельности педагогов и врачей осуществлялась с использованием метода экспертных оценок. В качестве критериев эффективности в ходе экспертного оценивания были задействованы стандартные показатели, заложенные в процедуру профессиональной аттестации педагогов и врачей.

Математические методы обработки данных: описательная статистика (среднее арифметическое - Мх, стандартное отклонение, коэффициент вариации), критерии сравнения U-Манна-Уитни, коэффициент корреляции $r$ Спирмена, метод корреляционных плеяд.

\section{Результаты}

Как следует из проведенного выше анализа, в рамках эмпирического исследования мы пытаемся показать, что развитие системы саморегуляции профессиональной деятельности осуществляется в соответствии с базовыми принципами оперативности и в то же время обладает своей спецификой. При этом специфика должна проявляться на количественном (общий уровень развития 
системы), качественном (преимущественное развитие отдельных компонентов системы) и структурном (конфигурация взаимосвязей компонентов системы) уровнях анализа.

1. Количественный и качественный анализ системы саморегуляции. В рамках данного анализа мы сравним уровень развития отдельных компонентов системы саморегуляции а) врачей и педагогов; б) педагогов начальной и старшей школы; в) врачей общей практики и хирургов.

Полученные данные свидетельствует, что процессуальные компоненты системы саморегуляции деятельности врачей развиты значимо выше, чем аналогичные компоненты системы саморегуляции деятельности педагогов $(\mathrm{Mx}=5.73$ и $\mathrm{Mx}=5.01$ соответственно, при $p<0.001)$, а личностные компоненты имеют обратное соотношение: у педагогов они развиты значимо выше, чем у врачей $(\mathrm{Mx}=5.65$ и $\mathrm{Mx}=4.38$ соответственно, при $p<0.001)$ (см. рисунок 1$)$.

Сравним уровень развития компонентов системы саморегуляции деятельности педагогов. Анализ показывает, что значимые различия между уровнем развития процессуальных компонентов саморегуляции учителей начальной и старшей школы отсутствуют ( $\mathrm{Mx}=5.06$ и $\mathrm{Mx}=4.99$ соответственно). Однако существуют значимые различия между личностными компонентами саморегуляции: они лучше развиты у учителей старшей школы $(\mathrm{Mx}=5.49$ и $\mathrm{Mx}=$ 5.73 соответственно, при $p<0.05)$ (см. рисунок 2 ).

Рисунок 1

Уровень развития компонентов системы саморегуляции деятельности врачей и педагогов

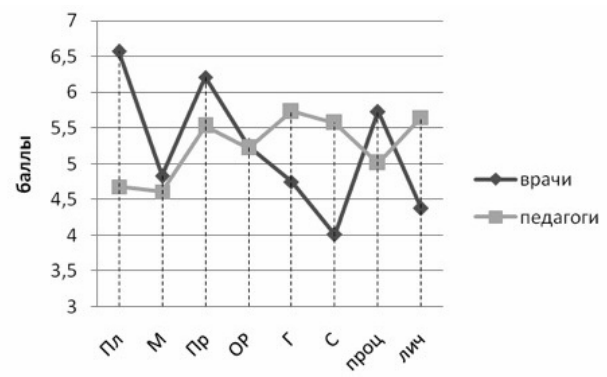

Рисунок 2

Уровень развития компонентов системы саморегуляции деятельности учителей начальной и старшей школы

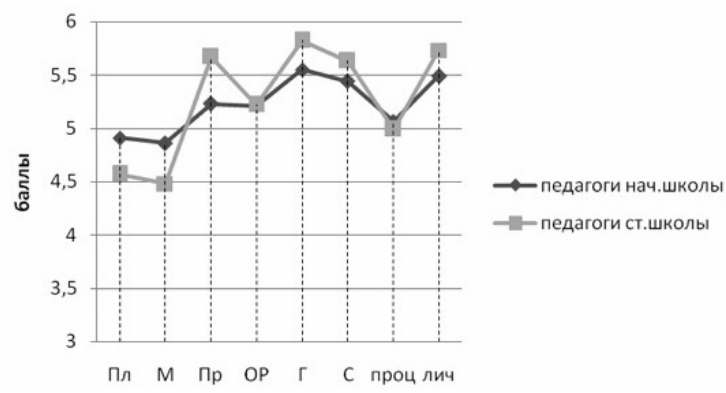


Сравнительный анализ уровня развития компонентов системы саморегуляции деятельности врачей демонстрирует сходные тенденции. Обнаружены значимые различия (при $p<0.05)$ между уровнем развития процессуальных $(\mathrm{Mx}=5.49$ и $\mathrm{Mx}=5.96$ соответственно $)$ и личностных $(\mathrm{Mx}=4.14$ и $\mathrm{Mx}=4.61$ соответственно) компонентов системы саморегуляции деятельности у врачей общей практики и хирургов, т.е. у последних они развиты лучше (см. рисунок 3).

Таким образом, сравнительный анализ развития системы саморегуляции относительно разнородных (врачи и педагоги) и однородных (учителя начальной и старшей школы, врачи общей практики и хирурги) видов профессиональной деятельности позволяет констатировать следующее.

1. Системы саморегуляции разнородных видов деятельности значимо $(p<0.001)$ отличаются друг от друга как на качественном, так и на количественном уровне. При этом необходимо отметить и качественную специфику развития отдельных компонентов саморегуляции деятельности у представителей однородных и разнородных профессий. Так, у обеих групп врачей наблюдается значимо более высокий уровень развития процессуальных компонентов системы саморегуляции в сравнении с личностными компонентами. У всех педагогов наблюдается обратная тенденция: у них значимо более высоко развиты личностные компоненты системы саморегуляции деятельности в сравнении с процессуальными.

2. Системы саморегуляции однородных видов деятельности незначительно отличаются количественно $(p<0.05)$ и не отличаются качественно. Так, у учителей начальной и старшей школы, несмотря на некоторые различия в уровне развития их систем саморегуляции, общая конфигурация выраженности компонентов системы совпадает, т.е. в обеих группах педагогов более развитыми являются личностные компоненты, а менее развитыми - процессуальные. Сходная тенденция прослеживается и в группе врачей. При наличии некоторых различий в уровне развития отдельных компонентов системы саморегуляции у терапевтов и хирургов у них также сохраняется общая конфигурация выраженности компонентов, т.е. и у тех и у других более развитыми являются процессуальные компоненты и менее развитыми личностные.

Рисунок 3

Уровень развития компонентов системы саморегуляции деятельности врачей общей практики и хирургов

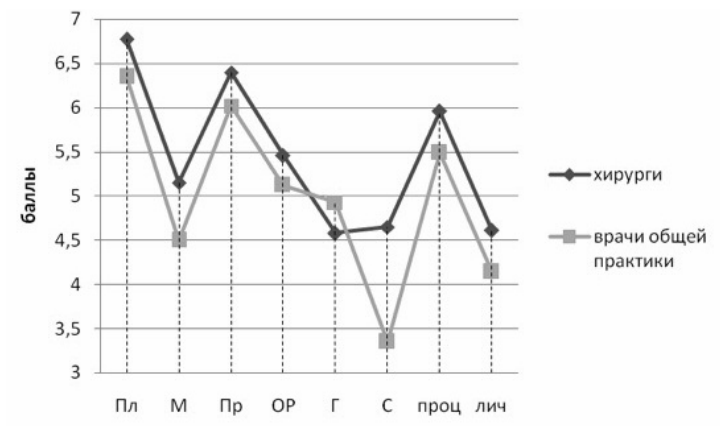


Полученные данные свидетельствуют о том, что мы наблюдаем существенные качественные и количественные отличия в уровне развития компонентов системы саморегуляции разнородных видов профессиональной деятельности (врачи и педагоги) и незначительные различия в количественных показателях, но сходство на качественном уровне развития систем саморегуляции однородных видов деятельности (учителя начальной и старшей школы, а также врачи общей практики и хирурги).

2. Структурный анализ системы саморегуляции. В ходе структурного анализа систем саморегуляции деятельности мы использовали следующие количественные показатели.

1. Интегративность системы саморегуляции. Данный показатель позволяет судить об общем уровне организованности системы; он подсчитывается как сумма значимых положительных корреляционных связей между всеми компонентами.

2. Интегрированность компонентов системы саморегуляции. Данный показатель свидетельствует о степени включенности отдельных компонентов в структуру, об их роли и месте в структуре; подсчитывается как сумма значимых положительных связей каждого компонента системы (компоненты, имеющие максимально высокие показатели интегрированности, определяются как базовые).

3. Связь компонентов системы саморегуляции с эффективностью профессиональной деятельности - компоненты, демонстрирующие максимальные связи с эффективностью, определяются как ведущие

Обратимся к анализу полученных эмпирических данных. Сравним разнородные виды профессиональной деятельности. Уровень интегративности системы саморегуляции врачей (52 балла) в 1.5 раза выше, чем у педагогов (34 балла) (рисунок 4). Базовую роль в системе саморегуляции врачей (по уровню интегрированности) играют процессуальные компоненты планирования, моделирования, программирования и личностный компонент «самостоятельность». В системе саморегуляции педагогов базовую роль выполняют процессуальный компонент «оценка результатов» и личностный компонент «гибкость».

Рисунок 4

\section{Степень интегрированности компонентов в систему саморегуляции деятельности} врачей и педагогов

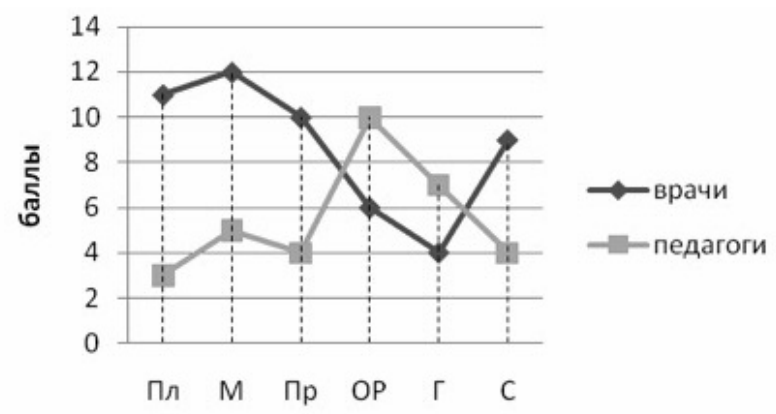


Представленные данные свидетельствуют о том, что система саморегуляции врачей более развита, чем у учителей, а также о том, что они опираются в ходе саморегуляции на разные процессуальные и личностные компоненты.

Проанализируем однородные виды профессиональной деятельности. Сравнивая две группы педагогов, можно констатировать, что уровень интегративности системы саморегуляции деятельности учителей старшей школы (34 балла) в 2.5 раза выше, чем у учителей начальной школы (12 баллов). Но, несмотря на различия по уровню интегративности, базовая роль в системах саморегуляции педагогов обеих групп отводится одному и тому же процессуальному компоненту («оценка результатов») (рисунок 5).

Относительно сходная ситуация наблюдается при сравнении двух групп врачей. У хирургов интегративность системы саморегуляции (44 балла) в 1.8 раза выше, чем у врачей общей практики (24 балла). При этом базовая роль в структуре саморегуляции отводится практически одним и тем же процессуальным компонентам (планированию и моделированию) (рисунок 6).

Таким образом, результаты структурного анализа в основном совпадают с данными предыдущего анализа и заключаются в следующем. Во-первых, зафиксировано, что системы саморегуляции разнородных видов деятельности

Рисунок 5

Степень интегрированности компонентов в систему саморегуляции деятельности педагогов начальной и старшей школы

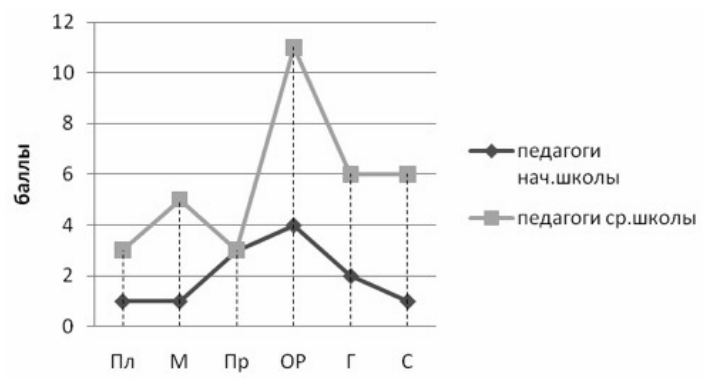

Рисунок 6

Степень интегрированности компонентов в систему саморегуляции деятельности хирургов и врачей общей практики

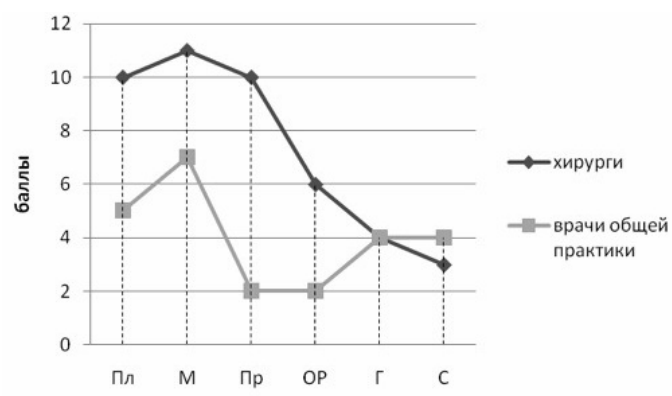


(врачи и учителя) существенно отличаются друг от друга как по уровню общего развития системы (уровень интегративности), так и по содержанию процессуальных и личностных компонентов, используемых в качестве базовых. Во-вторых, установлено, что системы саморегуляции однородных видов деятельности (учителя начальной и старшей школы; врачи общей практики и хирурги) различаются количественно по общему уровню выраженности развития интегративности, но принципиально сходны по тому, какие процессуальные и личностные компоненты системы выступают в качестве базовых.

3. Анализ корреляционных плеяд. Изучение корреляционных плеяд ориентировано на то, чтобы конкретизировать и представить в наглядной форме закономерности развития системы саморегуляции, выявленные выше (рисунки 7, 8, 9). Анализ корреляционных плеяд позволяет констатировать следующие моменты.

Система саморегуляции врачей является более интегрированной и организованной (см. рисунок 7), что соответствует результатам количественного анализа, проведенного выше. Все процессуальные и личностные компоненты включены в систему саморегуляции и обладают сильными связями. На рисунке показано, что базовыми в системе саморегуляции являются процесс моделирования и близкие к нему по уровню интегрированности процессы планирования и программирования. Они своими связями структурируют всю систему и определяют характерный способ саморегуляции, опирающийся на подготовку к деятельности, прогнозирование и антиципацию. Данный способ мы называем прогностическим.

Количество и сила связей в системе саморегуляции педагогов существенно ниже, что свидетельствует о более низком уровне ее интегративности и организованности. Рисунок 7 демонстрирует, что базовая роль в системе саморегуляции педагогов отводится процессу оценки результатов. И это указывает на то, что учителя в меньшей степени стремятся регулировать деятельность в процессе ее осуществления и не акцентируют внимания, как врачи, на подго-

Рисунок 7

Взаимосвязь компонентов системы саморегуляции деятельности врачей и педагогов

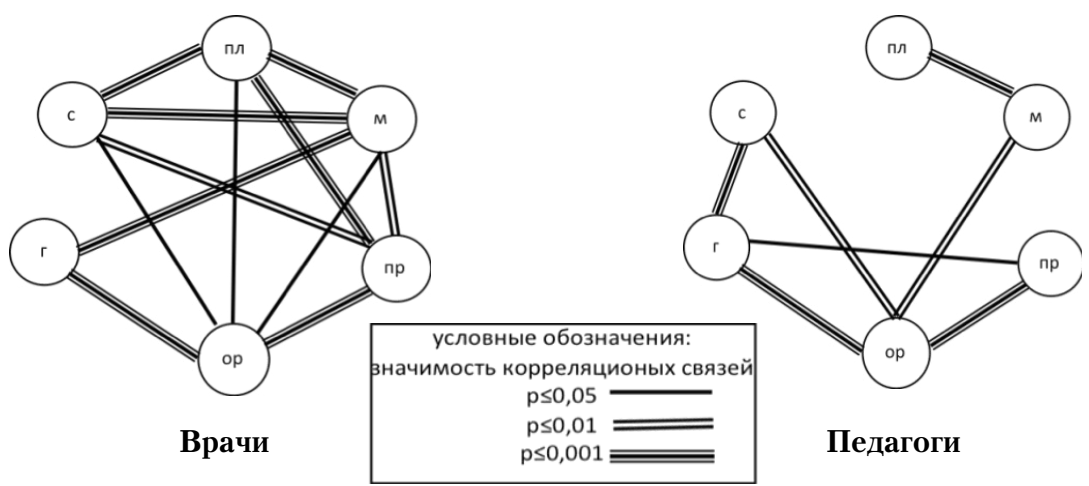


товительной работе, на антиципации и прогнозировании. Этот способ мы называем результативным.

Сравнительный анализ корреляционных плеяд хирургов и врачей общей практики (рисунок 8) показывает, что по уровню интегративности и организованности система саморегуляции хирургов развита значительно больше, а система саморегуляции врачей общей практики теряет целостность. Однако, несмотря на количественные различия в той и другой системе саморегуляции, базовая роль отводится моделированию и планированию. Это означает, что преобладающий способ саморегуляции у хирургов и врачей общей практики совпадает, следовательно, речь может идти лишь о частичных различиях двух систем саморегуляции врачей.

Структуры корреляционных плеяд педагогов начальной и старшей школы (рисунок 9) также различаются между собой лишь количественно. Уровень

Рисунок 8

Взаимосвязь компонентов системы саморегуляции деятельности хирургов и врачей общей практики

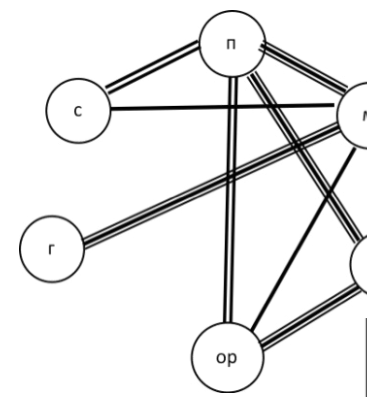

Хирурги условные обозначения: начимость корреляционых связей $\mathrm{p} \leq 0,05$ p $\leq 0,01$ $\mathrm{p} \leq 0,001$

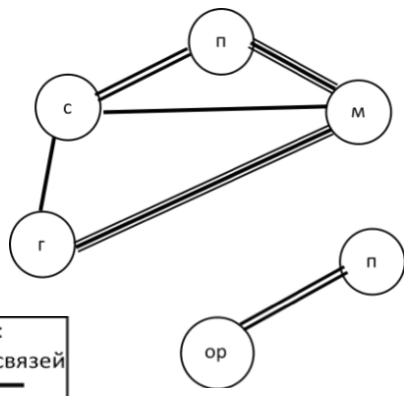

Врачи общей практики

Рисунок 9

Взаимосвязь компонентов системы саморегуляции деятельности учителей начальной и старшей школы

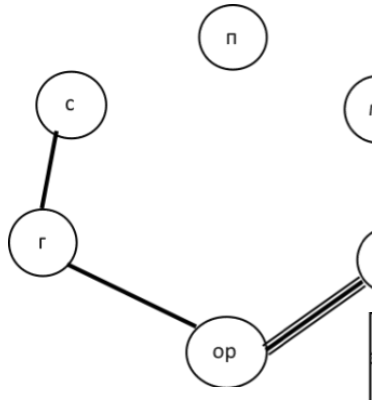

Учителя начальной школы

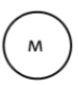

условные обозначения: вначимость корреляционых связей p $\leq 0,05$ $\mathrm{p} \leq 0,01$ $\mathrm{p} \leq 0,001$

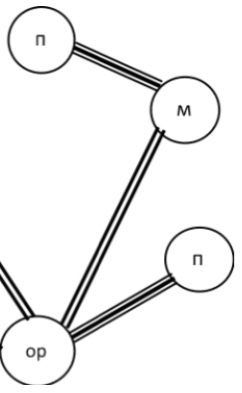

Учителя старшей школы 
интегративности и организованности системы саморегуляции педагогов старшей школы существенно выше. На это указывает наличие значительно большего количества связей, которые структурируют их систему саморегуляции. Система саморегуляции учителей начальной школы упрощается, теряет целостность и приобретает линейную форму. Однако в обеих группах учителей базовым является один и тот же процесс - оценка результатов. Следовательно, у педагогов начальной и старшей школы преобладает общий способ саморегуляции, в определенном смысле противоположный способу саморегуляции врачей.

Кратко обобщая результаты проведенного анализа, отметим следующее. На функционирование системы саморегуляции врачей влияет способность выявлять и представлять, анализировать и учитывать объективные и субъективные факторы, значимые для достижения целей. Это позволяет эффективно планировать и программировать деятельность и до ее начала подготовиться к тем сложным или критическим ситуациям, которые могут возникать по ходу ее выполнения.

Педагоги, в отличие от врачей, придают меньшее значение анализу и прогнозированию значимых условий, планированию и программированию деятельности. Поэтому на функционирование саморегуляции как динамической системы влияет, прежде всего, способность анализировать и оценивать результаты собственной деятельности. Именно активный самоконтроль определяет специфику системы саморегуляции педагогов, которые акцентируют свое внимание не на подготовке к деятельности, а на ее реализации.

Подводя итог проведенному анализу, отметим, что у врачей на функционирование системы саморегуляции влияет способность представлять систему внешних и внутренних значимых условий для достижения целей как в текущей ситуации, так и в перспективном будущем. А для педагогов, в свою очередь, на структуру саморегуляции деятельности влияет способность оценивать себя, результаты своей деятельности и поведения, определять субъективные критерии оценки успешности достижения результатов.

Несмотря на различия в уровне интегративности и интегрированности систем саморегуляции деятельности сходных специальностей, базовые компоненты их структур не изменяются. Для врачей общей практики и хирургов в качестве базового компонента системы саморегуляции деятельности выступает моделирование, а для учителей начальной и старшей школы - оценка результатов деятельности.

4. Взаимосвязь компонентов структуры саморегуляции с эффективностью деятельности. Анализ этих взаимосвязей позволяет нам ответить на следующие вопросы: насколько важна и необходима система саморегуляции для эффективного выполнения профессиональной деятельности? Какие компоненты системы саморегуляции играют в этом отношении ведущую роль? Обратимся к анализу полученных данных.

Установлено, что у врачей с эффективностью профессиональной деятельности связаны следующие компоненты системы саморегуляции: моделирование $(r=0.234 ; p=0.01)$, программирование $(r=0.253 ; p<0.01)$, оценка результатов 
$(r=0.296 ; p<0.001)$, гибкость $(r=0.274 ; p<0.01)$, самостоятельность $(r=0.245$; $p<0.01)$. Таким образом, взаимосвязь с эффективностью деятельности врачей демонстрируют большинство компонентов системы саморегуляции.

Согласно принятой нами терминологии, эти компоненты системы саморегуляции являются ведущими по отношению к эффективности профессиональной деятельности.

У педагогов выделен только один ведущий компонент, связанный с эффективностью профессиональной деятельности, и это процесс оценки результатов $(r=0.161 ; p<0.01)$. Значимых взаимосвязей эффективности профессиональной деятельности с другими компонентами системы саморегуляции у педагогов не обнаружено.

Представленные результаты свидетельствуют о том, что именно у врачей, для которых характерен высокий уровень развития системы саморегуляции, обнаруживаются наиболее тесные связи ее компонентов с эффективностью профессиональной деятельности. У педагогов мы наблюдаем обратную картину. У них зафиксированы более низкий уровень развития системы саморегуляции и минимально возможное количество связей ее компонентов с эффективностью профессиональной деятельности.

Другими словами, в целом прослеживается следующая закономерность: чем выше уровень развития системы саморегуляции, фиксируемый на количественном, качественном и структурном уровне, тем более тесно связаны ее компоненты с эффективностью профессиональной деятельности.

Полученные результаты позволяют выдвинуть предположение, которое важно, на наш взгляд, для понимания логики развития оперативности систем саморегуляции. Возможно, низкий уровень развития системы саморегуляции деятельности педагога определяется тем, что она слабо влияет на эффективность ее выполнения, и поэтому ее развитие не является актуальной проблемой для педагога. Действительно, зачем развивать то, что не значимо с точки зрения решения профессиональных задач.

Одна из возможных причин такого положения дел заключается в том, что другие факторы, связанные с предметом, условиями и содержанием деятельности педагога, которые трудно прогнозировать, нивелируют конструктивную роль саморегулятивных процессов. Можно предположить, что эти факторы делают как бы бесполезными усилия человека, направленные на саморегуляцию деятельности.

Конечно, данные факторы не отменяют необходимости и возможности саморегуляции вообще, но они меняют ее акценты и направленность. Происходит снижение роли прогностической саморегуляции, предваряющей деятельность, которая опирается на процессы планирования, анализа ситуации и программирования. С другой стороны, внимание педагога акцентируется на саморегуляции, опирающейся на процесс оценки и на анализ промежуточных и конечных результатов, получаемых в ходе профессиональной деятельности

Именно этим обстоятельством можно объяснить то, что наиболее развитым и интегрированным в системе саморегуляции деятельности педагога 
является компонент «оценка результатов», именно он связан с эффективностью педагогической деятельности.

\section{Обсуждение результатов}

Полученные данные и проведенный анализ убеждают нас в том, что системы саморегуляции деятельности педагогов и врачей развиваются и функционируют в полном соответствии с базовыми принципами оперативности. Это означает, что данные системы саморегуляции количественно, качественно и структурно различаются между собой, а их специфика, уровень прагматичности и лаконичности, особенности функциональной деформации и адекватности определяются содержанием, условиями и задачами конкретных типов и видов профессиональной деятельности.

Сказанное подтверждается полученными в ходе эмпирического исследования фактами, которые указывают на следующее.

Действительно, все системы саморегуляции исследованных нами видов профессиональной деятельности обладают определенной специфичностью. Причем их специфичность возрастает по мере увеличения различий между видами профессиональной деятельности, саморегуляцию которых эти системы обеспечивают. Максимальные различия в развитии систем саморегуляции мы обнаруживаем при сравнении разнородных видов профессиональной деятельности (врачи и педагоги). Эти различия сохраняются, но существенно снижаются, когда мы сравниваем однородные, т.е. более близкие по содержанию, виды профессиональной деятельности, такие как учителя начальной и старшей школы, а также врачи общей практики и хирурги.

Об оперативности развития систем саморегуляции исследованных видов профессиональной деятельности свидетельствует не только уровень специфичности, но и другие особенности ее проявления. Данные особенности обнаруживаются в том, что системы саморегуляции разнородных видов профессиональной деятельности (врачи и педагоги) различаются между собой количественно, качественно и структурно, а системы саморегуляции однородных (педагоги начальной и старшей школы; врачи общей практики и хирурги) - в основном лишь количественно.

Количественная специфика систем саморегуляции проявляется в преобладающем уровне развития а) отдельных компонентов системы саморегуляции; б) подсистемы процессуальных компонентов; в) подсистемы личностных компонентов и т.д.

На качественном уровне специфика развития систем саморегуляции находит свое выражение а) в дифференциации компонентов системы по уровню развития; б) в преимущественном развитии процессуальных или личностных компонентов системы; в) в формировании характерного типа саморегуляции и т.д.

Структурные различия в развитии систем саморегуляции выражаются а) в уровне общей интегративности, организованности систем; б) в уровне интегрированности (базовая роль) отдельных компонентов системы; в) в специфике структуры взаимосвязей компонентов системы и т.д. 
Оперативность развития систем саморегуляции исследованных видов профессиональной деятельности прослеживается и на уровне взаимосвязей их компонентов с эффективностью профессиональной деятельности. Уровень развития системы саморегуляции либо повышается, либо снижается в зависимости от той роли, которую она играет в процессе выполнения профессиональной деятельности. У врачей система саморегуляции тесно связана с эффективностью профессиональной деятельности, и поэтому она активно ими развивается. Система саморегуляции педагогической деятельности слабо связана с ее эффективностью, и поэтому, возможно, она развита значительно меньше. В этом проявляются прагматичность развития систем саморегуляции деятельности и их адекватность решаемым задачам.

Оперативность развития систем саморегуляции профессиональной деятельности проявляется в том, что представители разнородных профессий вырабатывают специфические способы осуществления саморегуляции, соответствующие особенностям их профессиональной деятельности. Как было показано выше, способ саморегуляции врачей в основном носит прогностический характер и опирается на процессы, которые обеспечивают эффективную подготовку к выполнению деятельности (предварительный анализ ситуации, планирование, программирование). Педагоги используют как бы противоположный способ саморегуляции. Они в ходе саморегуляции акцентируют внимание не на подготовке к профессиональной деятельности, а на оценке промежуточных и конечных результатов, получаемых в ходе ее выполнения. Нетрудно заметить, что эти изменения свидетельствуют не только о прагматичности и специфичности, но и проявлении конструктивной функциональной деформации развития систем саморегуляции.

О прагматичности, специфичности, лаконичности и функциональной деформации развития систем саморегуляции свидетельствует качественное совпадение способов организации саморегуляции у однородных видов профессиональной деятельности. Несмотря на определенные, прежде всего количественные отличия систем саморегуляции врачей общей практики и хирургов, в ходе профессиональной деятельности они реализуют одинаковый, характерный для врачей способ саморегуляции, который мы назвали прогностическим. Как было отмечено выше, системы саморегуляции педагогов начальной и старшей школы также отличаются друг от друга количественно. Тем не менее и те и другие используют качественно и структурно одинаковый способ саморегуляции деятельности, характерный именно для педагогов и отличный от способа, применяемого врачами. Мы назвали этот способ саморегуляции результативным. 


\section{Литература}

Ананьев, Б. Г. (1977). О проблемах современного человекознания. М.: Наука.

Карпов, А. В. (2007). Понятия метакогнитивных и интегральных процессов как концепты психологии саморегуляции. В кн. В. И. Моросанова (ред.), Субъект и личность в психологии саморегуляции (с. 46-67). М./Ставрополь: ПИ РАО/СевКавГТУ.

Конопкин, О. А. (2005). Структурно-функциональный и содержательно-психологический аспекты осознанной саморегуляции. Психология. Журнал Высшей школы экономики, 2(1), 27-42.

Конопкин, О. А. (2007). Механизмы осознанной саморегуляции произвольной активности человека. В кн. В. И. Моросанова (ред.), Субъект и личность в психологии саморегуляиии (с. 12 30). М./Ставрополь: ПИ РАО/СевКавГТУ.

Моросанова, В. И. (ред.). (2007). Субъект и личность в психологии саморегуляиии. М./Ставрополь: ПИ РАО/СевКавГТУ.

Моросанова, В. И. (2010). Индивидуальные особенности осознанной саморегуляции произвольной активности человека. Вестник Московского университета. Серия 14. Психология, 1, 36-45.

Моросанова, В. И., Бондаренко И. Н. (2015). Диагностика саморегуляиии человека. М.: Когито-Центр.

Моросанова, В. И., Коноз, Е. М. (2000). Стилевая саморегуляция поведения человека. Вопросы психологии, 2, 118-127.

Ошанин, Д. А. (1970). Предметное действие как информационный процесс. Вопросы психологии, 3, 34-50.

Ошанин, Д. А. (1977). Концепция оперативности в инженерной и общей психологии. В кн. Инженерная психология: Теория, методология, практическое применение (с. 131-145). М.: Наука.

Ошанин, Д. А. (1999). Предметное действие и оперативный образ: Избранные психологические труды. М./Воронеж: Московский психолого-социальный институт/НПО «МОДЭК».

Поваренков, Ю. П. (2016). Системогенетический подход к выделению и классификации профессиональных задач личности. Ярославский педагогический вестник, 2, 127-134.

Поваренков, Ю. П. (2017). Многообразие видов и форм деятельности (активности) профессионала (Часть 1). Ярославский педагогический вестник, 2, 187-193.

Поваренков, Ю. П. (2018). Определение и классификация деятельностно важных качеств профессионала. В кн. Ю. П. Поваренков (ред.), Системогенез учебной и профессиональной деятельности (с. 22-31). Ярославль: РИО ЯГПУ.

Шадриков, В. Д. (2007). Проблемы системогенеза профессиональной деятельности. М.: Логос.

Шадриков, В. Д. (2010). Профессиональные способности. М.: Университетская книга.

Шадриков, В. Д. (2013). Психология деятельности человека. М.: Институт психологии РАН.

Ссылки на зарубежные источники см. в разделе References после англоязычного блока.

Поваренков Юрий Павлович - профессор, кафедра общей и социальной психологии, ФГБОУ ВО «Ярославский государственный педагогический университет им. К.Д. Ушинского», доктор психологических наук, профессор.

Сфера научных интересов: психология профессионального и карьерного развития личности. Контакты: y.povarenkov@yspu.org

Цымбалюк Анна Эдуардовна - доцент, кафедра общей и социальной психологии, ФГБОУ ВО «Ярославский государственный педагогический университет им. К.Д. Ушинского», кандидат психологических наук.

Сфера научных интересов: психология карьерного развития личности.

Контакты: tsumba@inbox.ru 


\title{
Operativeness of Development of the Self-Regulation System of Professional Activity
}

\author{
Yu.P. Povarenkov ${ }^{\mathrm{a}}$, A.E. Tsymbaluk ${ }^{\mathrm{a}}$ \\ Yaroslavl State Pedagogical University named after K.D. Ushinsky, 108/1 Respublicanskaya Str., \\ Yaroslavl, 150000, Russian Federation
}

\begin{abstract}
The article is devoted to the acute problem of studying operativeness of personal professional development. The article shows that the founder of the theory of operativeness is D.A. Oshanin, who investigated the figurative forms of manifestation of operativeness. The next stage in the development of the theory of operativeness is associated with the name of V.D. Shadrikov. By means of theoretical and empirical analysis, he showed that not only the operational image, but also the subsystem of professionally important personality traits is developed in accordance with the principles of operativeness. This article attempts to empirically prove that the formation and realization of the system of self-regulation of professional activity is also subordinate to the principles of operativeness. For this purpose, the authors carried out a theoretical analysis of the concept of operativeness and defined it. The approach to understanding self-regulation of activity, which is implemented in the study, is outlined. A comparative empirical analysis of the self-regulation systems of the activities of general practitioners and surgeons, as well as elementary and high school teachers, is carried out. On the quantitative, qualitative, and structural levels, the specifics of the development of self-regulation systems for various types of professional activity are determined. Statistically significant correlations between the level of development of the components of the self-regulation system and the efficiency of activity are revealed. It was shown that the more activities differ from each other, the more the self-regulation systems differ from each other as well, primarily at the qualitative and structural levels. The results were used to prove the operativeness of development of the self-regulation system of activities.
\end{abstract}

Keywords: operativeness of professional development, conscious self-regulation of professional activity, self-regulation system, general abilities.

\section{References}

Ananiev, B. G. (1977). O problemakh sovremennogo chelovekoznaniya [On the issues of contemporary science of man]. Moscow: Nauka. (in Russian)

Baumeister, R. F., \& Vohs, K. D. (Eds.). (2004). Handbook of self-regulation: Research, theory and applications. New York: Guilford Press.

Butler, D. L., \& Winne, P. H. (1995). Feedback and self-regulated learning: a theoretical synthesis. Review of Educational Research, 65(3), 245-281.

Carver, C. S., \& Scheier, M. F. (2003). A self-regulatory perspective on personality. In T. Millon \& M. J. Lerner (Eds.), Comprehensive handbook of psychology: Personality and social psychology (Vol. 5, pp. 185208). New York: Wiley.

Karpov, A. V. (2007). Ponyatiya metakognitivnykh i integral`nykh protsessov kak kontsepty psikhologii samoregulyatsii [Notions of metacognitive and integral processes as the concepts of psychology of selfregulation]. In V. I. Morosanova (Ed.), Sub"ekt i lichnost'v psikhologii samoregulyatsii [Subject and personality in the psychology of self-regulation] (pp. 46-67). Moscow/Stavropol: PI RAO/SevKavGTU. (in Russian) 
Konopkin, O. A. (2005). Conscious self-control: the structure/function and content aspects. Psychology. Journal of Higher School of Economics, 2(1), 27-42. (in Russian)

Konopkin, O. A. (2007). Mekhanizmy osoznannoi samoregulyatsii proizvol’noi aktivnosti cheloveka [Mechanisms of conscious self-regulation of the voluntary human activity]. In V. I. Morosanova (Ed.), Sub"ekt i lichnost'v psikhologii samoregulyatsii [Subject and personality in the psychology of self-regulation] (pp. 12-30). Moscow/Stavropol: PI RAO/SevKavGTU. (in Russian)

Morosanova, V. I. (Ed.). (2007). Sub”ekt i lichnost'v psikhologii samoregulyatsii [Subject and personality in the psychology of self-regulation]. Moscow/Stavropol: PI RAO/SevKavGTU. (in Russian)

Morosanova, V. I. (2010). Individual differences of self-regulation of human voluntary activity. Moscow University Bulletin (Vestnik). Seria 14. Psychology, 1, 36-45. (in Russian)

Morosanova, V. I., \& Bondarenko, I. N. (2015). Diagnostika samoregulyatsii cheloveka [Diagnostics of human self-regulation]. Moscow: Kogito-Tsentr. (in Russian)

Morosanova, V. I., \& Konoz, E. M. (2000). Self-regulation of person's behavior style. Voprosy Psikhologii, 2, 118-127. (in Russian)

Oshanin, D. A. (1970). Predmetnoe deistvie kak informatsionnyi protsess [Objective act as an informational process]. Voprosy Psikhologii, 3, 34-50. (in Russian)

Oshanin, D. A. (1977). Kontseptsiya operativnosti v inzhenernoi i obshchei psikhologii [The concept of operativeness in engineering and general psychology]. In Inzhenernaya psikhologiya: Teoriya, metodologiya, prakticheskoe primenenie [Engineering psychology: Theory, methodology, application] (pp. 131-145). Moscow: Nauka. (in Russian)

Oshanin, D. A. (1999). Predmetnoe deistvie i operativnyi obraz: Izbrannye psikhologicheskie trudy [Objective act and operative image: Selected psychological works]. Moscow/Voronezh: Moskovskii psikhologosocial'nyi institut/NPO "MODEK”. (in Russian)

Povarionkov, Yu. P. (2016). The systemic genetic approach to allocate and classify the identity's professional tasks. Yaroslavskii Pedagogicheskii Vestnik, 2, 127-134. (in Russian)

Povarionkov, Yu. P. (2017). Variety of the professional's activity types and forms (Part I). Yaroslavskii Pedagogicheskii Vestnik, 2, 187-193. (in Russian)

Povarionkov, Yu. P. (2018). Opredelenie i klassifikatsiya deyatel'nostno vazhnykh kachestv professionala [Definition and classification of the important qualities of professional activity]. In Yu. P. Povarionkov (Ed.), Sistemogenez uchebnoi i professional'noi deyatel'nosti [Systemogenesis of learning and professional activity] (pp. 22-31). Yaroslavl: Yaroslavl State Pedagogical University named after K.D. Ushinsky. (in Russian)

Schunk, D. H., \& Zimmerman, B. J. (2003). Self-regulation and learning. In W. M. Reynolds \& G. E. Miller (Eds.), Handbook of psychology. Educational psychology (Vol. 7, pp. 59-79). Hoboken, NJ: John Wiley \& Sons.

Shadrikov, V. D. (2007). Problemy sistemogeneza professional'noi deyatel'nosti [Issues of systemogenesis of professional activity]. Moscow: Logos. (in Russian)

Shadrikov, V. D. (2010). Professional'nye sposobnosti [Professional abilities]. Moscow: Universitetskaya kniga. (in Russian)

Shadrikov, V. D. (2013). Psikhologiya deyatel'nosti cheloveka [The psychology of human activity]. Moscow: Institute of Psychology of the RAS. (in Russian)

Yuri P. Povarenkov - professor, chair of general and social psychology, Yaroslavl State Pedagogical University named after K.D. Ushinsky, D.Sc., professor.

Research area: psychology of professional and career development of personality.

E-mail: y.povarenkov@yspu.org

Tsymbaliuk Anna Eduardovna - associate professor, chair of general and social psychology, Yaroslavl State Pedagogical University named after K.D. Ushinsky, Ph.D.

Research area: psychology of career development of personality.

E-mail: tsumba@inbox.ru 